\title{
Effectiveness of a Rational Behavioral Emotive Program in Reducing Test Anxiety among University Students with High Academic Achievement
}

\author{
Najla Y. AlAmry \\ Assist. Professor of Psychology, \\ College of Education, \\ Princess Nourah Bint Abdulrahman University, \\ Saudi Arabia
}

Doi: 10.36941/jesr-2020-0057

Abstract

The present study aims to identify the effectiveness of a rational behavioral emotive program in reducing test anxiety among university students with high academic achievement in Riyadh. The author adopted the quasi-experimental approach. The sample comprised (26) students with high academic achievement who were encountering test anxiety at Princess Nourah bint Abdulrahman University (PNU) in Riyadh. The participants were divided into two groups: An experimental group of (13) students and a control group of (13) students. The author also used the test anxiety scale (Spielberger, 1972) and designed the rational behavioral emotive program using new electronic applications. The results showed statistically significant differences between the average scores of the experimental group students in the pre and posttests in favor of the posttest. There were statistically significant differences between the average scores of the two groups in the posttest of the scale in favor of the experimental group. Furthermore, there were no statistically significant differences between the average scores of the experimental group in the post and successive tests of the scale.

Keywords: Rational behavioral emotive counseling, test anxiety, university students with high academic achievement

\section{Introduction}

Anxiety is a fundamental concept in psychology and psychopathology, as well as a common symptom of mental disorders and physical diseases. In addition, it is the most prominent characteristic of neurosis and numerous behavioral disorders. Currently, university students encounter various problems associated with anxiety, complicated relationships, depression, and suicide attempts, which have increased (Velayudhan, Gayatridevi, and Bhattacharjee, 2010).

Burns (2004) reports that achievement tests play a prominent role as the most adopted method to define the learner's achievement throughout all educational levels. A test is a primary tool for measuring the university students' comprehension of the courses included in the academic programs. Test anxiety is an uncomfortable and unpleasant experience before, during, or after the test because of the individual's fear and horror (Egbochuku, 2008). The author contends that the issue gets more complicated at the university because it is a new stage that involves many new experiences, different methods of learning and evaluation, and curricula. Furthermore, it defines the individual's future and career. Therefore, university students should have counseling and preventive programs that minimize 
their psychological problems and emotive disorders, as well as help them achieve psychological, academic, and social adjustment.

Some studies indicate a high level of test anxiety among university students (Kavanagh, Ziino, and Mesagno, 2016). Its manifestations, represented in the cognitive, emotive, and physiological aspects, are high (Nelson, Lindstrom, and Foels, 2014). University students are increasingly exposed to test anxiety because of their various assessments over their studies. As a result, some students may encounter test anxiety which increases during test periods because they feel frightened of failure to fulfill their university goals (Sud and Prabha, 2004). Test anxiety extensively harms students because of its negative impact on their academic performance and health. Students with high levels of test anxiety show low achievement, so they suffer from further psychological problems causing their drop out of the university (Taylor and Deanne, 2002).

Studies have indicated that high achievers show a high level of anxiety compared to those with average academic achievement (Götz \& Hall, 2013). Velayudhan et al. (2010) assert the importance of providing counseling services for undergraduate students, especially at medical colleges, to help them build self-confidence and resilience and reduce anxiety and depression. The student who suffers from test anxiety thinks irrationally, illogically, and negatively. Test anxiety is a partial case of anxiety, which denotes the student's psychological, physiological, and cognitive symptoms because she/he expects failure to pass the test. Some authors explain test anxiety as a response to the student's negative internal dialogue (Stoeber, 2004).

Recently, the importance of cognitive aspects has emerged in estimating the individuals' emotions, as well as their psychological and social adaptation. Albert Ellis's theory of rational emotive behavioral therapy substantially focuses on the rational cognitive aspect and partially on the behavioral aspect, as well as the interaction between ideas, feelings, and behaviors of individuals. It is one of the prominent theories that employ the mental cognitive aspect. The author considered it when designing the counseling program of the present study.

Ellis (1980) claims that irrational thoughts are assessments derived from assumptions and suggestions in an absolute language and in sentences used to express need vocabulary and necessity verbs. They are the outcome of destructive and illogical ideas, generalizations, and expectations based on a mixture of thought and exaggeration. They cause anxiety and hinder achieving goals. Furthermore, they cause emotive and psychological disorders.

Counseling programs in the field of rational behavioral emotive counseling are based on overcoming the irrational thoughts and beliefs and negative emotions that defeat the individual (Prochaska and Norcross, 2006). Several studies assert the importance of providing counseling programs for undergraduate students to overcome test anxiety (Canu, Elizondo, and Broman-Fulks, 2017; Lowe, 2018; Sung, Chao, and Tseng, 2016). University students strongly need counseling programs to reduce test anxiety which results from challenges, pressures, as well as the diverse tasks and responsibilities they have to organize and fulfill. Moreover, the university is a pivotal stage in the individual's life where one's achievement defines a career, taking into consideration the GPA of the academic years. Accordingly, it is important to provide students with counseling that helps them reduce symptoms of anxiety, overcome its causes, positively affect both the psychological and academic aspects, and develop their performance using theoretical and applied programs.

\section{Statement of the Problem}

Tests play a significant role in the students' life because they are one of the fundamental evaluations, which cause fear and anxiety. Test anxiety has special importance because it defines the students' academic future, career, and social position. It is one of the most complicated psychological problems facing not only the student but the whole family, as well. All family members experience this problem (Al-Tayyib, 1994). Currie (2014) argues that most students experience various levels of test anxiety.

Several authors stress the importance of investigating test anxiety to help students reduce 
anxiety which they experience more than before because of their frequent stress and age circumstances. As a result, test anxiety affects students and their families (Driscall, 2007; Aydin, 2009) and prevails among university students (Canu et al., 2017; Lowe, 2018). Thus, appropriate therapy methods have to be adopted (Nelson et al., 2014).

Compared to their actual mental abilities, some students achieve less in some situations involving stress and evaluation, such as tests. This type of anxiety is called "test anxiety". It indicates a type of general anxiety that appears in tests and evaluations, where students feel disturbed, anxious, and restless. It may be associated with high rather than low achievement. Hence, some studies address test anxiety among students with high academic achievement. For example, Lupkowski and Schumacker (1991) indicated the high level of mathematics test anxiety among talented university students. Nithiya (2018) examined the effect of a behavioral intervention program on the neurologic aspect of the high achievers suffering from test anxiety.

However, other studies showed no relationship between mathematics anxiety and the student's grades. Lupkowski and Schumacker (1991) and Vuk and Morse (2013) revealed statistically significant differences between high and low achievers in self-efficacy and the ability to perform a test. However, no differences were evident in test anxiety.

Sung et al. (2016) contended that further researches and studies on test anxiety and achievement shall be conducted. The study addressed test anxiety, stress, personal characteristics of the examinees, and methods of assessment as well as their effect on performance. Students in the lower-achievement group exhibited a positive correlation between anxiety and achievement, which is consistent with the motivational enhancement model. Canu et al. (2017) illustrated that college students with attention-deficit/hyperactivity disorder (ADHD) were high-functioning, yet experienced higher test anxiety. Furthermore, Alam (2013) exhibited higher academic performance among university students with high test anxiety (males and females in rural and urban areas).

Most studies indicated a high level of test anxiety among females compared to males. For instance, Currie (2014) and Lowe (2018) exhibited statistically significant differences between males and females. Several studies illustrated a higher level of mathematics test anxiety among females compared to males (Alam, 2013; Lupkowski and Schumacker, 1991; Nelson et al., 2014). Kavanagh et al. (2016) indicated no difference in test anxiety between the Australian and American participants.

Velayudhan et al. (2010) reported that psychological counseling and guidance help students understand themselves as well as the surrounding world and handle anxiety more effectively. Lowe (2018) and Nelson et al. (2014) asserted the importance of counseling and therapy interventions of test anxiety among university students as well as the effect of interventions on test anxiety.

Group counseling programs of the rational behavioral emotive therapy are based on stopping and refuting the irrational thoughts and negative emotions that defeat the individual through reorganizing perceptions and thoughts to think logically and to identify the feelings and emotions resulting from exposure to disturbing situations (Prochaska and Norcross, 2006). Rational emotive behavioral therapy, in the interpretation of test anxiety, is based on the assumption that exposure to a stressor (A: Activating Event) does not cause a disturbance, but the type of belief (B: Belief) of this factor defines the final result (C: Consequence) (Corey, 1996).

Rational emotive behavioral therapy clarifies the relationship between the event, irrational thoughts, the consequences of feeling miserable and anxious, as well as the accompanying physiological and negative changes that influence the individual's life. It also provides the person with the skills and techniques that help get rid of anxiety (Al-Khawaja, 2013). Ellis and Abrams (1994) claim that the individual develops disorder through beliefs, coding and decoding of events, experiences, as well as classifying them as sad, painful, or disturbing. One is responsible for the emotive disturbances only.

Tatum, Lundervold, and Ament (2006) revealed that the effect of brief relaxation exercises on test anxiety stresses the need for further studies on behavioral training and therapeutic interventions for university students who encounter test anxiety. Nithiya (2018) asserted the positive effect of relaxation on test anxiety among high achievers. 
Working as a faculty member in a Saudi university and participating in the evaluation of female students, the author identified the problem of the present study. She noticed the frequent complaints from the high achievers during the achievement tests representing the emotive symptoms, irrational ideas, and negative behaviors that affect them psychologically, physically, and educationally. Also, she observed their tremendous efforts to overcome anxiety and prepare for the tests. Accordingly, she identified the need for counseling programs that reduce test anxiety and provide them with guidance and study skills to improve their academic performance, achievement, adjustment, and mental health. The problem of the present study is defined in the following question: What is the effectiveness of the rational behavioral emotive program in reducing test anxiety among university students with high academic achievement in Riyadh?

\section{Objectives}

The present study aims to prepare a rational behavioral emotive program to reduce test anxiety among university students and to assert its effectiveness in reducing test anxiety among university students with high academic achievement in Riyadh, Kingdom of Saudi Arabia.

\section{Significance}

\subsection{Theoretical significance}

- The study addresses the fundamentals of designing and developing group programs that use modern technology and reduce test anxiety as well as the topics, techniques, and modern technologies that benefit educationalists, psychologists, and specialists in guidance and psychological counseling in designing and developing counseling therapy programs.

- It enriches the Arab library and literature as most studies that handled counseling programs focused on anxiety, not test anxiety. Various studies recommended conducting further studies and researches on therapy interventions and counseling programs to reduce test anxiety among university students.

- To the author's knowledge, this study is the first to cover test anxiety among university students with high academic achievement. Most studies reported that test anxiety among females is higher than males. In addition, former Arabic studies focused on the high stage.

\subsection{Applied significance}

- The study defines the effectiveness of the counseling program test in reducing test anxiety among university students with high achievement. The test involves modern technologies and electronic applications that help the student adapt psychologically, cognitively, emotively, behaviorally, and socially. Furthermore, it develops the students' abilities and educational skills and qualifies them for other academic and professional stages.

- Few experimental studies addressed the field application of the counseling programs of test anxiety among university students, in general, and the outstanding students, in particular. To the author's knowledge, Saudi statistics, researches, and studies exhibit that most studies are descriptive.

- University guidance and counseling centers can apply the results of the program to the university students. Several studies recommended conducting further studies on therapy and counseling programs of test anxiety at the university. 


\section{Definition of Terms}

\subsection{Counseling program}

It is a set of organized and specialized steps, which aim to achieve specific goals. Each step leads to the next. Therefore, they seem connected and modify or replace the student's wrong behaviors and negative knowledge. The program is designed according to scientific fundamentals that provide direct and indirect counseling services individually or collectively to achieve normal growth and mental health (Zahran, 2011, p.439).

\subsection{Test anxiety}

The present study adopts the definition of Spielberger (1989) of test anxiety as "a personality trait in a specific situation involving discomfort, emotion, and fear of failing the exam". It is a type of anxiety associated with the test situation, which causes fear and distress. As it increases, a person becomes incapable of performing well in the test. It is a complicated term consisting of three aspects: A cognitive aspect that denotes the student's thinking of failing the test and the consequences, such as position and appreciation loss; the emotive aspect that represents the students' feeling of distress, tension, and panic from tests; the behavioral aspect that comprises negative behaviors in tests. Procedurally, it is the score of the university student with high achievement on the test anxiety scale adopted in the study.

\subsection{University students with high achievement}

The author defines them as the students enrolled in the second, third, and fourth years in 2017/2018 at the College of Education, PNU and obtained GPA (4) or above in their courses because it is the approved criterion of high-achievement in the Academic Counseling Unit at the College.

\section{Limitations}

The study was limited to:

Objective limits: Designing and verifying the effectiveness of a rational behavioral emotive program in reducing test anxiety among university students with high academic achievement.

Spatial limits: College of Education, PNU in Riyadh.

Temporal limits: A field study was conducted in the second semester of the academic year 2017/2018.

Human limits: Students with high academic achievement at the College of Education, PNU in Riyadh.

\section{Theoretical Framework and Literature Review}

Test anxiety is a form of general anxiety, which is associated with a specific situation experienced by the student. It denotes a single psychological problem reflecting fear of failure. It hinders storing and retrieving information because of receiving fewer pieces of information. Moreover, it results in poor performance, cognitive interference, and self-preoccupation rather than answering the questions. Thus, the student's academic performance worsens (Ibrahim and Askar, 1999, p.69).

Nicaise (1995) (cited in Sena, Lowe, and Lee, 2007) claimed that test anxiety represents a syndrome of behavioral, cognitive, and physiological responses that elicit negative feelings about the test situation. When one gets anxious, the circulatory system evokes, heartbeats increase, sweat glands secrete, and he/she feels frightened and restless. In addition, these physiological and cognitive responses may evoke negative feelings and perceptions about the test situation. Ritchwood, Carthron, 
and Decoster (2015) indicated low attention, concentration, and confidence, as well as mind-blanking during test anxiety. Moreover, there was a correlation between the higher levels of test anxiety and parents' and teachers' stress, as well as poor time management.

Test anxiety is an emotive psychological state that affects the student's psychological balance and ability to remember the information during the test. It also has psychological and physical symptoms, such as tension, unrest, and alert. Hence, a student feels frightened of not achieving the high expectations that he/she or parents aspire (Driscall, 2007).

The author argues that test anxiety does not denote the normal tension the individual experiences before the test. Rather, it is severe anxiety involving unjustified and exaggerated fear, panic, loss of control, nervosity, impotence, and pain, which hinder the student's thinking despite studying hard (Goldfried and Davison, 1994). Test anxiety is emotive reactions to the test. Such anxiety may be normal and a stimulant to the student. However, if it maximizes, it may cause confusion and fear, which result in various negative feelings accompanied by some psychological and physical side effects, such as not answering the test, headache, nausea, insomnia, and discomfort (Webb and Brigman, 2006).

Students with high test anxiety see the test as a threat, feel tense, do not trust themselves due to negative experiences, have negative self-autonomy, and undergo emotive tension. Thus, their concentration weakens. Many authors have asserted the necessity of identifying test anxiety's causes and treatment methods and designing therapy programs to overcome it and improve students' academic performance (Cassacly and Johnson, 2002; Lowe, 2018).

When the individual experiences test anxiety, he/she exhibits behavioral symptoms represented in avoiding the questions that cause anxiety or distraction and physiological symptoms including heart rate and pulse rate, sweat secretion, respiration rate, and dyspnea. He/she may show emotive symptoms, e.g. discomfort; disturbance, and fear of failure and social symptoms, such as social avoidance. These symptoms, according to this model, interact and affect academic self-efficacy.

Stenlund, Eklöf, and Lyrén (2017) showed differences in test-taking strategies between high and low achievers. High achievers reported using successful strategies to a higher extent. Furthermore, there were gender differences. For example, females reported using random guessing to a higher extent than males.

O'Donnell (2017) reported deficits in working memory associated with an earlier onset of test anxiety among university students. Currie (2014) demonstrated the need for the frequent practice of test-taking and its significant effect on the level of test anxiety. Espinosa, Tameta, and Castillo (2015) illustrated that students' readiness to take the test contributed to passing the moving examination and reducing test anxiety.

Rana and Mahmood (2010) showed that a cognitive factor (i.e. worry) contributed to test anxiety more than affective factors (emotions). Nithiya ( 2018) indicated that the left hemispheric anterior and posterior regions relate to and inversely affect the right hemispheric anterior and posterior brain activity. In addition, they were associated with the negative consequences of the anxiety situation. The results showed that left-sided brain activity is responsible for reducing test anxiety. Relaxation therapy reduces test anxiety and negative emotions.

Concerning the differences between males and females, theoretical frameworks and applied researches indicate that females report higher test anxiety than males. These results reveal that females when having tests, attempt to combat these threatening situations by negative adaptation, i.e. fear accompanied by emotive and physiological manifestations. This suggests that both genders suffer from test anxiety, but females report higher levels than males (Götz and Hall, 2013).

Most studies indicated that females report higher test anxiety than males. For example, Alam (2013) and Nelson et al. (2014) demonstrated that females showed higher test anxiety than males. Kavanagh et al. (2016) illustrated that females showed higher test anxiety than males among American and Australian university students.

In terms of test anxiety effect on the student, Burns (2004) stated that the experience of test anxiety affected university students, as well as their performance and perception. The results asserted 
the hypothesis of the relationship between test anxiety and performance expectations in the final exam, as well as the role of readiness for the test. Stenlund et al. (2017) demonstrated that test-taking behavior might bring additional variance to test scores.

Canu et al. (2017) illustrated that college students with ADHD were high-functioning, yet experienced higher test anxiety. Hong, Sas, and Sas (2006) asserted 3 areas in test anxiety: Test readiness, test-preparation awareness, and test-taking. Elicited constructs included cognitive, emotional, and motivational strategies and concentration. The authors discussed the need for strategy instructions to enhance the academic study and test-taking strategies and to address their motivational concerns.

In his survey which involved (284) university students, O'Donnell (2017) employed test anxiety and self-report scales of test anxiety and executive functioning. The results suggested that working memory deficits might be an early indicator of the development of test anxiety.

Concerning the effective methods and strategies to reduce test anxiety among university students, Birenbaum (2007) highlighted the need for a dialogue between instructors and students to structure expectations. Accordingly, the goals of higher education in the knowledge age could be achieved. Loncaric, Tatalovic, and Cepic (2015) emphasized the teacher's role in facilitating coping strategies for students' better learning outcomes and reducing test anxiety.

Kavanagh et al. (2016) aimed to ascertain the cross-cultural differences in test anxiety and personality characteristics (e.g. coping strategies and perfectionism) among (89) Australian and (143) American university students. The participants completed the scales of test anxiety, coping strategy, and perfectionism. Results indicated no difference in test anxiety between the Australian and American participants. Females were higher in test anxiety than males. Moreover, test anxiety was positively correlated with avoidant coping and socially prescribed perfectionism in both countries.

Currie (2014) aimed to identify levels of mathematics test anxiety. The sample comprised undergraduate business students enrolled in accredited higher education programs (Accreditation Council for Business Schools and Programs (25 years or above)). Tools involved 14-item mathematics anxiety scale which focused on the emotive responses and the psychological aspect of mathematics anxiety test, and self-report scale on the emotive experience of mathematics test anxiety according to a five-point Likert scale which was electronically applied, academic questions, and social as well as general data. The results exhibited statistically significant differences between males and females. Furthermore, mathematics anxiety test was significantly low among students enrolled in the courses compared to those who were not. They showed high academic achievement. The results also showed the need for the frequent practice of test-taking and its significant impact on test anxiety.

Several studies have asserted the need for counseling programs and therapy intervention to reduce test anxiety among university students. For example, Velayudhan et al. (2010) showed the efficacy of counseling in reducing anxiety and depression among medical students. They also indicated that counseling built self-confidence and the capacity to adjust and reduce anxiety and depression.

Loong (2012) exhibited the significant implications of academic guidance and counseling for the new local and international students. Nelson et al. (2014) recommended giving more concern to assessment methods and counseling interventions to treat test anxiety. Lowe (2018) also recommended conducting further studies on test anxiety among university students.

Various approaches can be adopted to reduce test anxiety, but the Rational Emotive Behavior Therapy (REBT) is the most effective. Anxiety results from frustration, which affects the individual's personality and lifestyle. REBT focuses on disclosing the irrational thoughts resulting from negative and improper feelings, which are replaced by proper and rational alternatives (Egbochuku, 2008).

In addition to relaxation techniques that reduce one's stressful behavior, the relaxation response is any technique (method) or procedure that helps him/her get relaxed. In other words, relaxation response replaces the anxiety response. However, without proper training on relaxation, a person cannot properly overcome test anxiety. Relaxation techniques are short-term and long-term. They help the individual relax and reduce test anxiety (Sharma, 2002). 
Tatum et al. (2006) reported the effect of abbreviated upright behavioral relaxation training (BRT) on test anxiety among college students. Results of the pilot study showed statistically significant differences in test anxiety and discomfort between the control and experimental groups in favor of the experimental group that received relaxation sessions. The study recommended a rapid relaxation training procedure for test anxiety. In addition, it highlighted the need for replication using a larger sample size with measurement of relaxed behavior and effect on academic performance.

Nithiya (2018) reported the positive effect of relaxation on test anxiety among high achievers. The study adopted the quasi-experimental approach and pre and posttests. A sample of five high achievers with the mean age of $\mathbf{1 6 . 2}$ years and a standard deviation of 1.64 was selected for the study. Results revealed that relaxation therapy reduced test anxiety by increasing the positive effect. The changes were functional but could be structural with long- term effects.

The techniques of REBT are:

- Cognitive techniques: They help the person change his/her irrational thoughts and replace them with logical, scientific, and rational ones (i.e. refutation, persuasion, encouragement, inspiration, reinforcement, and assignments).

- Emotive techniques: They involve one's feelings, emotions, reactions to various situations and stimuli, and experience, especially what is related to his/her problems. They are represented in role-play, modeling, and overcoming negative emotions (Surri, 2000).

- Behavioral techniques: They help the person get rid of the undesired behavior or modify and support it to a desirable one. They comprise assignments, procedural conditioning, reinforcement, punishment, and relaxation training (Al-Moghazi, 2012).

Some pieces of literature aimed to develop counseling programs for reducing test anxiety and asserting their effectiveness. The study sample comprised experimental and control groups. The results showed statistically significant differences between the average scores of the two groups in the posttest in favor of the experimental group.

Zettle (2003) aimed to assert the effectiveness of systematic desensitization in reducing mathematics test anxiety among (37) university students. Tatum et al. (2006) aimed to identify the effect of relaxation techniques on test anxiety among university students. The study adopted two selfreport measures of test anxiety: The Abbreviated Test Anxiety Scale (ATAS) and the Subjective Unit of Discomfort (SUD) rating scale. The sample comprised (20) self-referred college students. All participants completed the ATAS and were trained on the use of the SUD rating scale. Participants recorded SUD ratings in vivo over one week. At time 1 ( $\left.\mathrm{T}_{1}\right)$ assessment, the experimental group's participants received two group sessions of upright BRT, and the control group's participants simply recorded SUD ratings. At time 2 ( $\mathrm{T}_{2}$ ) assessment, all participants provided SUD rating data and completed the ATAS. Correlated t-tests indicated statistically significant differences in test anxiety and discomfort between the experimental and control groups in favor of the experimental group, which received relaxation sessions. The robust effect provided further evidence for the effectiveness of BRT in reducing test anxiety. The study recommended the application of abbreviated BRT when treating it.

Al-Awfi (2008) identified the effectiveness of a cognitive emotive behavior therapy program in reducing test anxiety among outstanding high-school students. The author designed a test anxiety scale. The sample comprised (30) outstanding students who suffered from test anxiety in the second high grade. Velayudhan et al. (2010) aimed to define the extent of the medical students' ability to cope up with anxiety and depression with the help of counseling services. In the quasi-experimental method (pre-posttest equivalent group design), Beck Anxiety Inventory and Beck Depression Inventory were administered to 120 medical students (30 males and 30 females in each group) who were randomly selected from a private medical college.

Sayyhi (2011) aimed to identify the effectiveness of an exam skills-based program in reducing test anxiety among (28) high school students. The author designed the test anxiety scale. Al-Khawaja (2013) aimed to develop and investigate the effectiveness of two programs of group counseling in 
reducing test anxiety. The first was based on the rational emotive behavioral approach, and the second was based on the relaxation approach. The study sample consisted of (22) students, randomly distributed to two groups of (11) students each at the College of Education, Sultan Qaboos University.

Bakr (2014) aimed to identify the effectiveness of a behavioral cognitive program in reducing test anxiety and its effect on improving some skills of academic achievement and study among secondary school students in the Arab Republic of Egypt. The study sample consisted of (32) students distributed to two groups. The author designed the study skills list and test anxiety scale.

Al-Rashidi (2014) investigated the effectiveness of a systematic desensitization strategy in reducing test anxiety and its effect on improving psychological adjustment among middle-school students with learning disabilities. The sample comprised (15) students. The author designed the test anxiety scale and used the personal-social adjustment scale of Al-Randy, As-Shiekh, Al-Anbary, and Al-Khalifa (1999).

Abu Hassouna (2015) aimed to identify the effect of a behavioral cognitive training program in reducing test anxiety among Irbid National University students in Jordan. The sample consisted of (28) students divided into two groups. Eissa (2016) explored the effectiveness of training in imagination directed at developing academic self-efficacy to reduce test anxiety among the $5^{\text {th }}$ grade primary pupils with learning disabilities in Riyadh. The sample comprised (40) students distributed to two groups.

Hamadata (2017) addressed the effectiveness of the counseling program in reducing test anxiety and improving study habits in a sample of outstanding students at the College of Education, Najran University. The sample comprised (20) students divided into two groups. Mahmoud (2018) aimed to identify the effectiveness of the academic resilience counseling program in reducing test anxiety among university students in the Arab Republic of Egypt. The sample consisted of (20) students. The author prepared two scales: One for academic resilience and the other for test anxiety.

The previous pieces of literature aimed to identify the effectiveness of different counseling approaches in reducing test anxiety. They involved behavioral cognitive, rational emotive behavioral, and realistic approaches, as well as group counseling. They also included Welby's theory of counseling, systematic desensitization technique, relaxation technique, and guided imagery training. The samples comprised students at different educational levels, but the majority were applied to high school students. The studies adopted the quasi-experimental approach. Similarly, most of the studies that were conducted in Saudi Arabia addressed test anxiety and were descriptive, i.e. they described levels of anxiety only. Experimental researches are too few and did not address university students. The results indicated statistically significant differences between males and females. In addition, females reported higher test anxiety than males despite the geographical diversity of the samples.

The author also observed that foreign studies were more specific in addressing the variable of test anxiety and classifying the student's problem according to the course. For example, they developed mathematics test anxiety, physics test anxiety, and practical test anxiety. Accurate identifying of the problem is a fundamental of measurement and evaluation in psychology.

The present study is consistent with the previous pieces of literature in using the quasiexperimental approach and rational emotive behavioral therapy, as well as the adopted methods and techniques. Moreover, it introduces electronic applications within the counseling program in accordance with modern technology and the requirements of the current era. However, it uses a different sample. To the author's knowledge, it is the first study to address test anxiety among university students with high academic achievement. Also, its spatial limitations are different.

\section{Hypotheses}

1. There are statistically significant differences between the average scores of the experimental group students in the pre and posttests of the test anxiety scale in favor of the post-test.

2. There are statistically significant differences between the average scores of the two groups in the posttest of the test anxiety scale in favor of the experimental group. 
3. There are no statistically significant differences between the average scores of the experimental group in the post and successive tests of the test anxiety scale.

\section{Methodology}

\subsection{Method}

The author adopted the quasi-experimental method (pre-posttest equivalent group design) because it is appropriate for achieving the objectives of the present study. Pre and posttests were given to the students of the experimental and control groups.

\subsection{Population}

The population covered the students of the College of Education at PNU, Riyadh in the second semester of $2017 / 2018$.

\subsection{Sampling}

The sample comprised (26) students with high academic achievement with test anxiety at Princess Nourah bint Abdulrahman University (PNU) in Riyadh. The participants were distributed to an experimental group of (13) students and a control group of (13) students.

Selection of the participants was conducted according to the following steps:

- Students, enrolled in the second, third, and fourth years in the academic year 2017/2018 and obtained GPA (4) or above in the courses of the previous year, numbered (104).

- The test anxiety scale was applied to students with high academic achievement to define the students' quadrants on the scale, as shown in table (1).

Table (1): Students' quartiles on the test anxiety scale

\begin{tabular}{|c|c|c|}
\hline Quadrants & Number of students & Score range \\
\hline Lowest & 26 & From 28 to 38 \\
\hline Second & 26 & From 39 to 53 \\
\hline Third & 26 & From 54 to 69 \\
\hline Highest & 26 & From 70 to 80 \\
\hline
\end{tabular}

The students who obtained the highest quadrant on the test anxiety scale were identified. They numbered (26). They were randomly distributed to two experimental and control groups according to specialization, academic year, and GPA, as shown in table (2).

Table (2): Distribution of the students of the experimental and control groups according to specialization, academic year, and GPA

\begin{tabular}{|l|l|c|c|}
\hline & & Experimental Group & Control Group \\
\hline \multirow{3}{*}{ Specialization } & Early childhood & 5 & 6 \\
\cline { 2 - 4 } & Special Education & 4 & 4 \\
\cline { 2 - 4 } & Psychology & 4 & 3 \\
\hline \multirow{3}{*}{ Academic Year } & Second Year & 4 & 3 \\
\cline { 2 - 4 } & Third Year & 4 & 6 \\
\cline { 2 - 4 } & Fourth Year & 5 & 4 \\
\hline \multirow{2}{*}{ GPA } & From 4 to less than 4.5 & 9 & 3 \\
\cline { 2 - 4 } & 4.5 and above & 4 & 10 \\
\hline
\end{tabular}


The author used the nonparametric Mann-Whitney $U$ test for the independent groups to homogenize the experimental and control groups in GPA and test anxiety before testing the counseling program to the experimental group students, as shown in tables (3) and (4).

Table (3): Results of the homogenization of the experimental and control groups' students in GPA.

\begin{tabular}{|l|c|c|c|c|c|c|}
\hline Group & No. & Average & Total & U Value & Z Value & Significance Level \\
\cline { 1 - 4 } Experimental & 13 & 12.92 & 168 & 77 & 0.39 & $\begin{array}{c}\text { o.69 } \\
\text { (Insignificant) }\end{array}$ \\
\hline Control & 13 & 14.08 & 183 & 77 & \\
\hline
\end{tabular}

Table (3) indicates that (Z) value equals (o.39), which is statistically insignificant. This finding suggests no statistically significant differences between the average scores of the students of the experimental and control groups in GPA before testing the counseling program among the experimental group students.

Table (4): Results of the homogenization of the experimental and control groups' students in test anxiety

\begin{tabular}{|l|c|c|c|c|c|c|}
\hline Group & No. & Average & Total & U Value & Z Value & Significance Level \\
\cline { 1 - 4 } Experimental & 13 & 14.96 & 194.5 & 65.5 & 0.99 & $\begin{array}{c}0.32 \\
\text { (Insignificant) }\end{array}$ \\
\hline Control & 13 & 12.04 & 156.5 & &
\end{tabular}

Table (4) shows that $(Z)$ value equals (o.99), which is statistically insignificant. This finding suggests no statistically significant differences between the average scores of the students of the experimental and control groups in test anxiety before testing the counseling program among the experimental group students.

\subsection{Tools}

\subsubsection{Test Anxiety Scale}

The author used the test anxiety scale (Spielberger, 1972). It is a self-report scale and comprises (20) items. The participant checks (never, sometimes, often, or always) to express the frequency of anxiety symptoms in the test. The grading instructions define one score for "never", two for "sometimes", three for "often", and four for "always". Accordingly, the scores of the test range (20-80). The score (20-39) denotes low test anxiety, (40 -59) shows moderate test anxiety, and (6o-80) clarifies high test anxiety.

The author asserted the validity of the internal consistency of the test anxiety scale through testing to a pilot sample of (43) students at PNU in Riyadh and estimating the values of Pearson correlation coefficients between each item and the total score. The values of correlation coefficients ranged (o.62-0.89) and were statistically significant.

- Correlation Coefficients of the Test Anxiety Scale

Table (5): Correlation coefficients between the items and the total score of the test anxiety scale (pilot sample: $\mathrm{N}=43$ )

\begin{tabular}{|c|c|c|c|}
\hline No. & Correlation Coefficients & No. & Correlation Coefficients \\
\hline 1 & $* * 0.7831$ & 11 & $* * 0.6033$ \\
\hline 2 & $* * 0.6832$ & 12 & $* * 0.6887$ \\
\hline 3 & $* * 0.7946$ & 13 & $* * 0.5993$ \\
\hline 4 & $* * 0.7303$ & 14 & $* * 0.7287$ \\
\hline
\end{tabular}




\begin{tabular}{|c|c|c|c|}
\hline No. & Correlation Coefficients & No. & Correlation Coefficients \\
\hline 5 & $* * 0.7213$ & 15 & $* * 0.7831$ \\
\hline 6 & $* * 0.6496$ & 16 & $* * 0.8395$ \\
\hline 7 & $* * 0.6509$ & 17 & $* * 0.8017$ \\
\hline 8 & $* * 0.7553$ & 18 & $* * 0.6692$ \\
\hline 9 & $* * 0.7219$ & 19 & $* * 0.7725$ \\
\hline 10 & $* * 0.8122$ & 20 & $* * 0.8280$ \\
\hline
\end{tabular}

** Statistically significant at the level of (o.o1)

The author asserted the reliability of the test anxiety scale by re-testing it to the participants of the pilot study after two weeks. She also estimated the Pearson correlation coefficient between their scores in the two tests. The reliability value was (o.84). It is high and indicates that the scale is reliable.

\subsubsection{Counseling Program (developed by the author)}

The program aims to reduce test anxiety in the light of behavioral cognitive therapy. It focuses on the cognitive, emotive, and behavioral aspects and identifies their procedures, as follows:

- The cognitive aspect (or worry): The individual is preoccupied with irrational and negative thoughts, failing the test and the consequences, including loss of status and appreciation. It involves the following:

- Define and refute irrational thoughts and reduce negative and irrational patterns of thinking by building sound cognitive aspects and adopting rational thinking methods.

- Create positive attitudes to learning and responsibility for learning by the learner.

- The emotive aspect: The individual suffers from distress, tension, panic, as well as other physiological symptoms represented by frequent thinking and feelings, techniques of selfassertion, role-play, and assignments.

- The behavioral aspect involves negative behaviors in tests. It denotes the following:

- Relax and learn to reduce anxiety, tension, and stress.

- Systematic desensitization to address conditionality.

- Program Objectives

Procedural objectives of the program are, as follows:

- Introduce students to rational emotive behavioral therapy and its techniques to reduce symptoms of test anxiety.

- Provide students with some cognitive aspects of test anxiety.

- Help students practice muscle relaxation.

- Help students practice stress and anxiety reduction techniques through gradual exposure to anxiety situations and training them on combating methods.

- Help students address test situation.

- Help students reshape their awareness of test situations.

- Develop skills of study, time management, and prioritization.

- Develop the skill of answering paper and electronic tests.

- Develop the skill of handling the electronic applications that contribute to the follow-up and development of the techniques and skills obtained in the program sessions and to contribute to modifying the cognitive, emotive, and behavioral aspects of test anxiety.

- Program Procedures

- Define and discuss the irrational thoughts related to test anxiety, teach, apply positive thinking patterns instead of the negative ones to combat test-related concerns, and deliver training to generalize them in test situations.

- Foster transformation and distraction technique to stop thinking of negative attitudes and to recall positive attitudes as well as imaginations instead of the negative ones. 
- Self-assertion skills, positive self-talk, and feedback.

- Muscle relaxation and assignments.

- Organized progressive immunization (systematic desensitization and positive reinforcement training).

- Training in the study as well as study skills and prioritization, which focus on learning style, effective learning strategy, and skills of test preparation, as well as answering objective and essay questions.

- Training in effective time management skills.

- Training in test-taking skills and strategies, such as the careful reading of the questions and using keywords, as well as test preparation skills.

- Number of sessions: 15 sessions distributed to 9 weeks.

- Session Duration: 6o to 90 minutes.

- Program Duration: One or two sessions per week. It was implemented in 9 weeks.

- Session Objectives: Objectives were introduced to the students at the beginning of each session.

- Aids and Methods

- Each session requires tables, boards, and technological aids, including video clips, PowerPoint, pictures, and hard copies.

- The appendix comprises the new electronic applications that were used to help students jot down and discuss information and thoughts and apply skills of emotive muscular nervous relaxation, meditation style, and distraction techniques.

- Counseling interventions using electronic applications include electronic questionnaires, electronic ideas tables, ideas and emotions modifying tables, task tables, anxiety curve, academic achievement graph, relaxation application, and team gathering.

- Work System: It involves the system of each session, whether small sub-groups, individual work, or group work.

- Training Methods: Discussion and dialogue, brainstorming, role-play, simulation, problem-solving, and relaxation.

- Session Evaluation: Participants received evaluation cards at the end of each session to express their opinions. In addition, the students discussed the benefits of the sessions and made further suggestions.

- Successive Test: Two months after the end of the counseling program, the successive tool was done, and a comparison was made between the average scores of the experimental group in the post and successive tests of the scale using the Wilcoxon test.

\section{Results and Discussion}

\subsection{Results of the first hypothesis}

To verify the first hypothesis, the author used Wilcoxon signed-rank test for the related groups to compare the average scores of the experimental group in the pre and posttests of the test anxiety scale, as shown in table $(7)$.

Table (7): Results of the Wilcoxon signed-rank test for the significance of differences in the average scores of the experimental group in the pre and posttests of the scale

\begin{tabular}{|l|l|c|c|c|c|c|}
\hline Test & Category & No. & Average ranking & Total of ranks & Z Value & Significance Level \\
\hline \multirow{3}{*}{ Pre-Post } & Positive & o & o & o & & \multirow{2}{*}{0.01} \\
\cline { 2 - 6 } & Negative & 13 & 7 & 91 & 3.19 & \\
\cline { 2 - 6 } & Equivalent & o & & & & \\
\hline
\end{tabular}


Table (7) exhibits that the (Z) value equals (3.19). It is statistically significant at the level of (o.o1) and suggests statistically significant differences in the average scores of the experimental group students in the pre and posttests of the test anxiety scale in favor of the posttest.

\subsection{Results of the second hypothesis}

To verify the second hypothesis, the author used Mann-Whitney U test of the independent groups to compare the average scores of the experimental and control groups in the posttest of the test anxiety scale, as shown in table (8).

Table (8): Results of Mann-Whitney U test of the significant differences in the average scores of the experimental and control groups in the posttest of the test anxiety scale

\begin{tabular}{|l|c|c|c|c|c|c|}
\hline Group & No. & Average ranking & Total of ranks & U Value & Z Value & Significance Level \\
\hline Experimental & 13 & 7 & 91 & \multirow{2}{*}{0} & \multirow{2}{*}{4.35} & \multirow{2}{*}{0.01} \\
\hline Control & 13 & 20 & 260 & & \\
\hline
\end{tabular}

Table (8) shows that $(\mathrm{Z})$ value equals (4.35). It is statistically significant at the level of (o.o1) and suggests statistically significant differences in the average scores of the experimental and control groups in the posttest of the test anxiety scale in favor of the experimental group.

\subsection{Results of the third hypothesis}

To verify the third hypothesis, the author used Wilcoxon signed-rank test for the related groups to compare the average scores of the experimental group students in the post and successive tests of the test anxiety scale, as shown in table (9).

Table (9): Results of Wilcoxon signed-rank test for the significance of differences in the average scores of the experimental group students in the post and successive tests of the scale

\begin{tabular}{|l|l|c|c|c|c|c|}
\hline Scale & Category & No. & Average ranking & Total of ranks & Z Value & Significance Level \\
\hline \multirow{3}{*}{ Post-successive } & Positive & 5 & 4.80 & 24 & & \multirow{2}{*}{0.37} \\
\cline { 2 - 6 } & Negative & 3 & 4 & 12 & 0.91 & (Insignificant) \\
\cline { 2 - 6 } & Equivalent & 5 & & & & \\
\hline
\end{tabular}

Table (9) shows that (Z) value equals (o.37). It is statistically significant and suggests no statistically significant differences in the average scores of the experimental group students in the post and successive tests of the test anxiety scale.

\section{Discussion}

The results can be discussed in the light of the techniques, activities, and pieces of training of the counseling program, which contributed to cognitive restructuring that helped students observe and modify their irrational beliefs and ideas regarding test situations and replace them with rational ideas that help them deal with test situations properly and alleviate the cognitive and emotive symptoms of test anxiety. Moreover, the program focused on the emotive aspect, awareness of the influence of emotions on the perception of behavior, and the role of substituting positive emotions to cope with symptoms of test anxiety. Behavioral skills played a role using the techniques of relaxation, systematic desensitization, and role-play. The participants also learned the skills of study, prioritization, and time management.

Electronic applications reinforced the skills and contributed to the cognitive emotive behavioral 
development using the activities, techniques, training, applications, and assignments to help the students overcome symptoms of test anxiety. The program helped them perceive and handle test situations positively. Furthermore, it developed test preparation and relevant strategies and behaviors. Results are consistent with Espinosa et al. (2015), reporting that students' preparation for the test helped them reduce test anxiety. They match the findings of Stenlund et al. (2017) that showed the role of using test-taking strategies in the achievement of the outstanding student and Hong et al. (2006) that asserted 3 areas in test anxiety: Test-preparation, test-preparation awareness, and test-taking. They agree with Ritchwood et al. (2015) that revealed a correlation between attention, concentration, time management, and confidence during the test, Birenbaum (2007) who indicated the effectiveness of the adopted strategies, as well as Abu Hassouna (2015), Al-Khawaja (2013), and Bakr (2013) that showed the effectiveness of using refutation, persuasion, encouragement, and relaxation in reducing test anxiety.

Systematic desensitization provided the students with more confidence, helping them handle the test situation and reduce test anxiety through overcoming the negative feelings and emotive physiological responses in tests. Tatum et al. (2006) revealed the effectiveness of systematic desensitization in reducing the emotive responses during anxiety situations. The results are consistent with Nithiya (2018) that reported the positive effect of relaxation on test anxiety among the students with high academic achievement and Tatum et al. (2006) who demonstrated the effect of abbreviated upright behavioral relaxation training on test anxiety among college students.

Relaxation techniques also increased the student's ability to overcome stressful situations, e.g. anxiety, through feeling relieved and controlling anxiety response. Its emotive release reduced test anxiety on exposure to the anxiety-related situation. This asserts that students' ability of resistance and perseverance increased compared to their reduced fear. This result is consistent with Sharma ( 2002) and Zettle ( 2003).

The role play technique helped students reconsider test situations that caused their discomfort. Also, they had a belief that test situations are expected and can be controlled. They also had the potential to control test situations on their own, make appropriate decisions, and effectively confront these situations. This result is consistent with Al-Awawi (2004), Hamadata (2017), and Mahmoud (2018), demonstrating the effectiveness of counseling in reducing test anxiety.

Moreover, lectures and group discussions contributed to raising the students' awareness and ability to express their feelings and suffering in test situations, justifying anxiety reasons, and identifying methods of overcoming. They also helped the students think rationally, develop proper beliefs on tests, and acquire more positive thinking styles to deal with test situations. This finding is consistent with Eissa (2016) who revealed the effectiveness of the guided imagery in reducing test anxiety, Rana and Mahmood (2010) who indicated that worry creates test anxiety and Kavanagh et al. (2016) who showed the effect adjustment methods on test anxiety.

Accordingly, the program affects the aspects of test anxiety. This finding is consistent with Loong (2012) Lowe (2018), Nelson et al. (2014), and Velayudhan et al. (2010) that asserted the significant effect of academic guidance, programs, counseling and support on university students. Constant effectiveness of the counseling program in reducing test anxiety among the participants after the follow-up period is explained in enhancing rational thoughts, training students in behavioral skills that reinforced their self-confidence and increased their ability to face test situations positively. The students acquired skills of study, revision, prioritization, test preparation, organizing the answer of objective and essay questions, problem-solving, time management, as well as management and organization of learning time effectively. Moreover, they were trained in reading the questions carefully and using keywords.

\section{Recommendations}

Based on its results, the study recommends:

1. Train new university students in self-learning methods and scientific thinking skills and 
provide them with the skills of proper study and university life to avoid anxiety.

2. Train university students in the techniques of reducing anxiety and rational thinking methods and skills as a preventive strategy to overcome test anxiety.

3. Design preventive therapy counseling programs to help university students overcome anxiety and to encourage them to adopt a positive philosophy in the face of life challenges.

\section{Further Studies}

The author recommends conducting the following studies:

1. A survey study on the courses that cause test anxiety among university students.

2. Effectiveness of an integrated counseling program in reducing test anxiety among new university students.

3. Effectiveness of a training program based on university life skills in reducing test anxiety among university students.

\section{Acknowledgement}

This research was funded by the Deanship of Scientific Research at Princess Nourah bint Abdulrahman University through the Fast - track research funding program.

\section{References}

Abu Hassouna, N. (2015). The effect of a behavioral cognitive training program in reducing test anxiety among the students of Irbid National University. The Islamic University Journal of Educational and Psychology Studies, $23(1), 158-182$.

Alam, M. (2013A study of test anxiety, self-esteem and academic performance among adolescents. IUP Journal of Organizational Behavior, 12(4), 33-43.

Al-Awfi, N. (2008). The effectiveness of a behavioral cognitive counseling program in reducing test anxiety in a sample of outstanding high school students (MA. thesis). College of Education, Taibah University.

Al-Khawaja, A. M.(2013). The effectiveness of a counseling program in reducing test anxiety in a sample of male students at Sultan Qaboos University. Journal of Educational and Psychological Sciences-University of Bahrain, 14 (3), 471-494.

Al-Moghazi, H. (2012). The effectiveness of rational emotive behavioral therapy in reducing depression in a sample of teachers. Journal of Counseling-Ain Shams University, 30, 237-273.

Al-Randy, R. As-Shiekh, Z., Al-Anbary, M. \& Al-Khalifa, E. (1999). Personal and social adjustment among middle school students in Kuwait using the California Test of Personality. Kuwait: Ministry of Education.

Al-Rashidi, M. (2014). The effectiveness of a counseling program in reducing test anxiety and its relationship to psychological adjustment in a sample of persons with learning disabilities. Journal of Reading and Literacy Egyptian Association for Reading and Literacy, 151, 167-207.

Al-Tayyib, M. (1994). Principles of mental health. Alexandria: Dar El Maaref.

Aydin, S. (2009). Test anxiety among foreign language learners: A review of literature. Journal of Language and Linguistic Studies, 5(1), 127- 137.

Bakr, N. (2014). The effectiveness of a behavioral cognitive program in reducing test anxiety and its effect on improving some study skills and academic achievement among secondary school students in Assiut (Ph.D. dissertation). Faculty of Education, Assiut University.

Birenbaum, M. (2007). Assessment and instruction preferences and their relationship with test anxiety and learning strategies. Higher Education, 53(6), 749-768. http://dx.doi.org/10.1007/s10734-005-4843-4.

Burns, D. (2004). Anxiety at the time of the final exam: Relationships with expectations and performance. Journal of Education for Business, 8o(2), 119-124.

Canu, W., Elizondo, M. \& Broman-Fulks, J. (2017). History of ADHD traits related to general test and specific math anxiety in college students. Learning and Individual Differences, 58, 56-63. https://doi.org/10.1016/j.lindif.2017.07.008.

Cassacly, J.\& Johnson, R. (2002). Cognitive test anxiety and academic performance. Contemporary Educational Psychology, 27 (2), 270-295. https://doi.org/10.1006/ceps.2001.1094. 
Corey, G. (1996). Theory and practice of counseling and psychotherapy. CA: Brooks-Cole Publishing Company.

Currie, L. (2014). Mathematics anxiety in adult undergraduate business students: A descriptive study (Ph.D. dissertation). Capella University, Minnesota.

Driscall, R. (2007). Westside test anxiety scale. Retrieved from https://eric.ed.gov/?id=ED495968.

Egbochuku, E. (2008). Efficiency of rational, emotive behavior therapy on the reduction of test anxiety among adolescents in secondary schools. European Journal of Social Sciences, 6 (4), 155-164. https://doi.org/10.108o/21507686.2017.1412329

Eissa, Y. (2016). The effectiveness of guided-imagery training in developing academic self-efficacy to reduce test anxiety among students with learning disabilities. Special Education Journal-Zagazig University, 16, 357-403.

Ellis, A. (1980). The principle and practice of rational emotive therapy. London: Jossy-Boss Inc.

Ellis, A. \& Abrams, M. (1994). Rational emotive behavior therapy in the treatment of stress management. British journal of guidanceE counseling, $22(1), 39-51$.

Espinosa, A., Tameta, A. \& Castillo, D. (2015). Test anxiety and moving examination in science laboratory classes. Pakistan Journal of Psychological Research, 30(2), 343-355.

Goldfried, M.\& Davison, G. (1994). Clinical behavior therapy (expanded ed.). New York: Wiley.

Götz, T. \& Hall, N. (2013). Emotion and achievement in the classroom. In: J. Hattie \& E. Anderman (eds.), International guide to student achievement (pp. 192-195). London: Routledge.

Hamadata, B. (2017). The effectiveness of a counseling program in reducing test anxiety and improving study habits in a sample of outstanding students at the College of Education, Najran University. Jordan Journal of Educational Sciences, 13 (1), 119-131.

Hong, E., Sas, M. \& Sas, J. (2006). Test-taking strategies of high and low mathematics achievers. The Journal of Educational Research, 99(3), 144-155,192.

Ibrahim, A. \& Askar, A. (1999). Clinical psychology in the field of psychiatry. Cairo: The Anglo-Egyptian Bookshop.

Kavanagh, B., Ziino, S. \& Mesagno, C. (2016). A comparative investigation of test anxiety, coping strategies and perfectionism between Australian and United States students. North American Journal of Psychology, 18(3), 555-570.

Loncaric, D., Tatalovic, S. Cepic, R. (2015). Pattern approach to coping with school failure for better learning outcomes: Reconsidering relationships between coping, personality, self-esteem and test anxiety. Proceedings from the $18^{\text {th }}$ International Academic Conference, London, doi: 10.20472/IAC.2015.018.076.

Loong, T. (2012). Self-regulated learning strategies and pre-university math performance of international students in Malaysia. Journal of International Education Research, 8(3), 223.

Lowe, P. (2018). The test anxiety measure for college students: Examination of its psychometric properties using an online survey with a Canadian sample. Canadian Journal of School Psychology, 33(4), $279-296$. https://doi.org/10.1177/o829573517725178.

Lupkowski, A. \& Schumacker, R. (1991). Mathematics anxiety among talented students. Journal of Youth and Adolescence, 20(6), 563-72. doi: 10.1007/BFo1537362.

Mahmoud, R. (2018). The effectiveness of a counseling program of academic resilience development in reducing test anxiety among university students (MA. thesis). Faculty of Arts, Zagazig University.

Nelson, J., Lindstrom, W. \& Foels, P. (2014). Test anxiety and college students with attention deficit hyperactivity disorder. Journal of Psychoeducational Assessment, 32(6), 548. https://doi.org/10.1177/0734282914521978.

Nithiya, A. (2018). Anterior and posterior regions of the brain in relation to test anxiety. Education Sciences $\mathcal{E}$ Psychology, 48(2), 48-56.

O'Donnell, P. (2017). Executive functioning profiles and test anxiety in college students. Journal of Psychoeducational Assessment, 35(5), 447. https://doi.org/10.1177/0734282916641554.

Prochaska, J. \& Norcross, J. (2006). Systems of psychotherapy: A transtheoretical analysis (6 ${ }^{\text {th }}$ ed). Pacific Grove, CA: Brooks-Cole.

Rana, R. \& Mahmood, N. (2010). The relationship between test anxiety and academic achievement. Bulletin of Education \& Research, 32(2), 63-74.

Ritchwood, T., Carthron, D. \& Decoster, J. (2015). The impact of perceived teacher and parental pressure on adolescents' study skills and reports of test anxiety. Journal of Best Practices in Health Professions Diversity, 8(1), 1006-1019.

Sayyhi, S. (2011). The effectiveness of a counseling program in reducing test anxiety among second high school students. Dirassat Journal- Algeria, 18, 119-128.

Sena, J., Lowe, P.\& Lee, S. (2007). Significant predictors of test anxiety among students with and without learning disabilities. Journal of learning disabilities, 40, 360-676.

Sharma, S. (2002). Anxiety in students. Psychological Studies, 47, 148-152.

Spielberger, C. (1972). Anxiety: Current trends in theory and research. New York: Academic Press. 
Spielberger, C. (1989). State-trait anxiety inventory: Bibliography ( $2^{\text {nd }}$ ed.). Palo Alto, CA: Consulting Psychologists Press.

Stenlund, T., Eklöf, H. \& Lyrén, P. (2017). Group differences in test-taking behaviour: An example from a highstakes testing program. Assessment in Education: Principles, Policy E Practice, 24(1), 4-20. https://doi.org/10.1080/0969594X.2016.1142935.

Stoeber, J. (2004). Dimensions of test anxiety: Relations to ways of coping with pre-exam anxiety and uncertainty. Anxiety StressE Coping, 17(3), 213-226. doi: 10.1080/10615800412331292615.

Sud, A. \& Prabha, I. (2004). Perfectionism, procrastination and test-anxiety. Journal of Community Guidance and Research, 21(3), 330-337.

Sung, Y., Chao, T. \& Tseng, F. (2016). Reexamining the relationship between test anxiety and learning achievement: An individual-differences perspective. Contemporary Educational Psychology, 46, $241-252$. https://doi.org/10.1016/j.cedpsych.2016.07.001.

Surri, E. (200o). Therapeutic psychology. Cairo: Alam Elkotob.

Tatum, T., Lundervold, D. \& Ament, P. (2006). Abbreviated upright behavioral relaxation training for test anxiety among college students: Initial results. International Journal of Behavioral ConsultationE Therapy, 2 (4), 475480 .

Taylor, J.\& Deanne, F. (2002). Development of a short form of the test anxiety inventory (TAI). The Journal of General Psychology, 129(2), 127-136.doi: 10.1080/00221300209603133.

Velayudhan, A., Gayatridevi, S. \& Bhattacharjee, R. (2010). Efficacy of behavioral intervention in reducing anxiety and depression among medical students. Industrial Psychiatry Journal, 19(1), 41-46. doi:http://dx.doi.org/10.4103/o972-6748.77636.

Vuk, J. \& Morse, D. (2013). Self-efficacy, test anxiety, and self-reported test-taking ability: How do they differ between high- and low-achieving students? Research in the Schools, 20(2), 28-34.

Webb, L.\& Brigman, G. (2006). Student success skills: Tools and strategies for improved academic and social outcomes. Professional School Counseling, 10(2), 112-120. https://doi.org/10.1177/2156759Xo601000215.

Zahran, H. (2001). Mental health and psychotherapy ( $3^{\text {rd }}$ ed.). Cairo: Alam Elkotob.

Zettle, R. (2003). Acceptance and commitment therapy (ACT) vs systematic desensitization in treatment of mathematics anxiety. Psychology Record, 53(2), l97-216. 